\title{
Mathematical Modeling with Middle School Students: The Robot Art Model-Eliciting Activity
}

\author{
Micah S. Stohlmann ${ }^{1 *}$ \\ ${ }^{1}$ University of Nevada, Las Vegas, UNITED STATES \\ *Corresponding Author: micah.stohlmann@unlv.edu \\ Citation: Stohlmann, M.S. (2017). Mathematical Modeling with Middle School Students: The Robot Art \\ Model-Eliciting Activity. European Journal of STEM Education, 2(2), 4. \\ https:/ / doi.org/10.20897/ejsteme.201704
}

Published: August 30, 2017

\begin{abstract}
Internationally mathematical modeling is garnering more attention for the benefits associated with it. Mathematical modeling can develop students' communication skills and the ability to demonstrate understanding through different representations. With the increased attention on mathematical modeling, there is a need for more curricula to be developed, implemented, and assessed. This study details the mathematical understandings that a diverse class of urban middle school students demonstrated on a mathematical modeling activity focused on geometry and measurement. At times students had difficulties in communicating clearly but based on the structure of the activity students were able to self-assess the quality of their communication and work towards improvement. The groups in the class were able to develop methods for how to program a robot to recreate a picture, though improvements could be made to the design of the activity. Teachers can use MEAs and mathematical modeling as formative assessment to build on students' understandings and further develop ideas that the teacher has in mind to pursue. Such assessment provides a rich basis for identifying evolving mathematical understandings that can be further developed.
\end{abstract}

Keywords: middle school, mathematical modeling, model-eliciting activities, geometry

\section{INTRODUCTION}

Internationally, mathematical modeling is gaining more of a presence in school standards and international documents. In Australia, mathematical modeling is part of the concepts and techniques that students should know in the National Mathematics Curriculum (Australian Curriculum, Assessment and Reporting Authority, 2015). In Sweden, mathematical modeling is one of seven mathematical abilities to develop in students. Germany includes mathematical modeling as one of six compulsory competencies (Blum \& Borromeo Ferri, 2009). The PISA 2012 mathematics framework describes mathematical literacy with many connections to mathematical modeling.

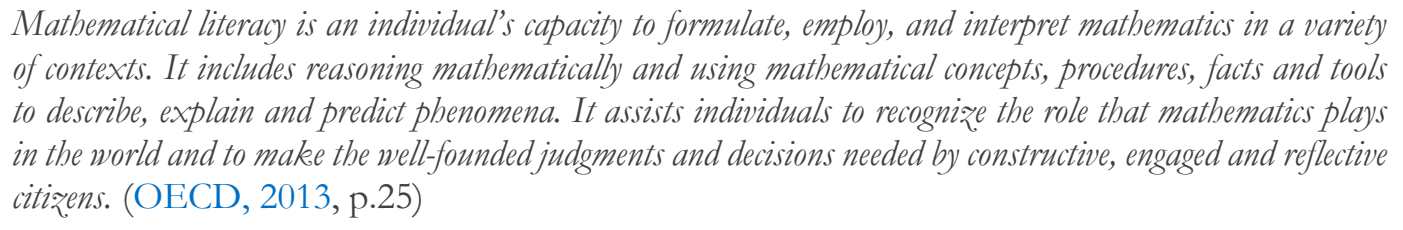

Mathematical Modeling is also one of eight Standards for Mathematical Practice in the U.S. Common Core State Standards for Mathematics (Common Core State Standards Initiative, 2010). Since mathematical modeling is 
often done in groups it develops students' ability for mathematical description, explanation, justification, and argumentation (English \& Watters, 2005). It can also increase their meta-representational knowledge; students' explicit recognition of why they represented their model in the way they did (English, 2010).

With the increased attention on mathematical modeling there is a need for curriculum to be developed and tested that is based on research-based principles (Stohlmann \& Albarracin, 2016). This study describes the mathematical understandings that a diverse group of urban middle school students demonstrated on a mathematical modeling activity as part of a Saturday STEM (Science, Technology, Engineering, and Mathematics) program offered at a large research university in the Southwestern part of the United States.

\section{THEORETICAL FRAMEWORK}

There are several mathematical modeling approaches that encompass a range of theoretical and pragmatics perspectives (Kaiser \& Sriraman, 2006). One of these perspectives is the contextual modeling perspective that has subject-related and psychological goals. This perspective draws on the design of activities that motivate students to develop the mathematics needed to make sense of meaningful situations. A perspective that is aligned with contextual modeling that was used in this study is the Models and Modeling Perspective (MMP).

One of the most important characteristics of the MMP is that experts in fields tend to not only do things differently, but they also see or interpret things differently. The development of these interpretation systems or models are an invaluable part of what it means to develop expertise in a field (Lesh, Carmona, \& Moore, 2009). In general, "models are conceptual systems (consisting of elements, relations, operations and rules governing interactions) that are expressed using external notation systems, and that are used to construct, describe, or explain the behaviors of other system(s)-perhaps so that the other system can be manipulated or predicted intelligently" (Lesh \& Doerr, 2003, p.10). In the MMP the abilities, processes and constructs to solve "real life" problems are used throughout the learning process and not only after the content is learned (Lesh \& Zawojewski, 2007). As students iteratively develop their solutions during modeling activities, so teachers can go through an iterative process in their development of these activities.

Aligned with the MMP the definition of mathematical modeling used in this study was that "mathematical modeling is an iterative process that involves open-ended, real world, practical problems that students make sense of with mathematics using assumptions, approximations, and multiple representations" (Stohlmann \& Albarracin, 2016, p.1). Mathematical modeling curriculum should have multiple acceptable solutions. Much work done with the MMP draws on Model-Eliciting Activities (MEAs) as the modeling curriculum used.

\section{Model-Eliciting Activities}

Model-Eliciting Activities (MEAs) are open-ended, realistic, client driven mathematical modeling activities that were originally designed as an alternative to standardized testing as a way for students to demonstrate mathematical knowledge (Lesh \& Doerr, 2003). MEAs are designed based upon six principles (Lesh, Hoover, Hole, Kelly, \& Post, 2000).

1. Model Construction: This principle ensures that students are required to construct an explicit description, explanation, or procedure for a mathematically significant situation. This is done through a problem statement that provides students with direction from a client on the focus of the problem.

2. Generalizability: In MEAs students are required to produce solutions that are shareable with others and modifiable for other closely related situations. In the problem statement students are directed to develop a model for the immediate situation being addressed and also generalize their model for other closely related situations.

3. Model documentation: This principle ensures that students are required to create some form of documentation that will reveal explicitly how they are thinking about the problem. This is done through student presentations in which they describe their developed model and the process of how they came up with it, which often involves multiple representations. It can also be accomplished through having students write letters, to the client in the problem, that details their model and rationale for the model.

4. Reality: MEAs should be posed in a realistic context and be designed so that students can interpret the activity meaningfully from their different levels of mathematical ability and general knowledge. MEAs can often be used across different grades of students because they assess what students know and understand on mathematical content that can develop across grade levels.

5. Self-assessment: This principle ensures that the activity contains criteria the students can identify and use to test and revise their current ways of thinking. Students should be able to self-assess how well their model meets the needs of the client. This can be done through information or data provided in the MEA, feedback from other group members and other groups, and testing the model with new data or for closely related situations. 
Table 1. Messages or questions for students when doing mathematical modeling

\begin{tabular}{l} 
Before mathematical modeling \\
There is more than one right answer to this problem. \\
There is not one type of person that is the best at mathematical modeling. Everyone can contribute. \\
Make sure everyone in your group understands your solution. \\
Use multiple ways to demonstrate your solution: pictures, graphs, symbols, words, or equations. \\
\hline During mathematical modeling \\
\hline Keep in mind what the problem is asking you to do. \\
Make sure everyone in your group understands your solution. \\
Does your solution make sense in the realistic situation? \\
Can your solution be improved? \\
Is your mathematics correct? \\
\hline Before group presentations
\end{tabular}

Before group presentations

Listen carefully to each group and think of a question to ask them.

Try to see if there is anything from a group that you can use in your solution.

Look to ensure that each group's mathematics is correct.

\begin{tabular}{l}
\hline After group presentations \\
\hline After hearing from other groups' ideas, can our solution be improved? \\
Is there any feedback we received to improve our solution? \\
Was our solution clearly explained? \\
\hline After mathematical modeling \\
\hline What mathematics did my group use in our solution? \\
How well did I understand the mathematics that was used? \\
How well did I do working in the group?
\end{tabular}

6. Effective prototype: MEAs are developed around "big ideas" in mathematics. This enables teachers to use MEAs as a formative assessment at the start of a new chapter and/or as a summative assessment to assess students' mathematical understandings.

MEAs are implemented starting with an opening article or video, then readiness questions to help students become familiar with the real-world context and the problem statement. Next students work in groups to solve the problem. They then present their ideas to the whole class. Finally, in their small groups they are given time for revision of their models and for reflection.

Through working with middle school teachers and students (Maiorca \& Stohlmann, 2016; Stohlmann, Maiorca, \& Olson, 2015) I have developed messages or questions to emphasize with students during the different parts of the implementation of mathematical modeling (Table 1). These ideas were emphasized and discussed with the middle school students in this study as they worked on the MEA.

\section{Mathematical Modeling with Middle School Students}

Middle school students can successfully participate in mathematical modeling activities and their abilities in mathematical modeling increase over time. In a study that used the Big Foot MEA with average ability middle school students, students progressed through stages of proportional reasoning development that have been observed over periods of several years (Lesh \& Doerr, 2003). Other studies done with average ability middle school students and MEAs have demonstrated that groups develop complex mathematical models that integrate multiple mathematics concepts (Lesh \& Carmona, 2003; McClain, 2003). This has been found to be the case as well with students in lower track mathematics classes once they have had prior experience with MEAs (Harel \& Lesh, 2003). In an experimental study, using a sequence of six MEAs over 3 months Mousoulides, Christou, \& Sriraman (2008) found that the experimental MEA group outperformed the control group on a modellng abilities test and the treatment was most effective for students with lower modeling abilities. Further studies have shown that middle school students successfully complete MEAs and use robust mathematical knowledge (Doerr \& English, 2003; Mousoulides, Pittalis, Christou, \& Sriraman, 2010).

While the research has shown that middle school students can successfully develop models, there are some groups that struggle with mathematical modeling. In completing the Natural Gas MEA, in which students are given data on annual average consumption for 15 years and have to predict when reserves will run out, four out of six groups of 12-year-old students developed models appropriate for solving the problem. Two groups failed to understand the concept of average and effectively use it in their models (Mousoulides \& English, 2011). In a study done with average ability $7^{\text {th }}$ graders who were doing mathematical modeling for the first time, about half of the groups had an acceptable model. The students completed the Historic Hotels MEA in which groups had to 
decide the best way to price a hotel room to maximize profit. All students understood the context and what the problem was asking and were able to use a systematic way to check profit from room price (Aliprantis \& Carmona, 2003). Other difficulties that middle school students have had with mathematical modeling include $6^{\text {th }}$ graders' discussions not refining their models (Mousoulides et al., 2007), $7^{\text {th }}$ to $9^{\text {th }}$ graders having difficulty choosing the most important variables and assumptions (Gould \& Wasserman, 2014), and several studies have found that if students lack needed mathematics knowledge it could cause a blockage (Galbraith \& Stillman, 2006; Ng, 2011; Stillman, Brown, \& Galbraith, 2010). Galbraith \& Stillman (2006) have also developed a framework for student blockages between six modeling steps with thirty-one general possible blockages. For example, a few of the possible blockages include being able to make relevant assumptions and clarifying the context of the problem. Connected to the possible blockages Stillman (2011) identified five metacognitive responses that students could have when faced with difficulties with four of these responses leading to unproductive results. The fifth response, routine metacognitive activity, allows students to self-assess the situation and make a productive decision in the process of creating their model.

In total, there have been positive results with middle school students and MEAs; though there is a need for more MEAs and mathematical modeling curriculum to be developed, implemented, and assessed. Though students may have some difficulties in working on mathematical modeling, their group members and other groups in the class can mitigate these difficulties to ensure that successful models can be developed.

\section{METHODS}

This study was conducted with 16 middle school students (age 11-13) that voluntarily enrolled in a Saturday STEM program at a large research university in the Southwestern part of the United States. The students were from a large urban school district. The purpose of the Saturday STEM program was to provide a series of inquiry experiences designed to provide interesting and exciting opportunities in STEM education. The program lasted five Saturdays and the results from this study are taken from the second Saturday of the program. The students did not have prior experience with mathematical modeling before participating in this program. On the first Saturday of the program, the students completed the Big Foot MEA in which students must determine the height of a person given footprints and stride length (Lesh \& Doerr, 2003).

The MEA used in this study was the Robot Art MEA (See Appendix). The MEA has an opening reading that discusses how an artist, Max Chandler, uses robots and mathematics to create his art. Next, students answer readiness questions based on the reading and to think about how robots can improve our lives. The problem statement for this MEA is given to the students by a client, the high school robotics team. They would like to have a robot be able to be given directions to recreate any picture. Students are given sample pictures to choose from to test out how to best give directions to a robot. One student in each group pretended to be the robot. They listened to the commands given to them by two other group members and did exactly as told. They used a pencil to draw based on the commands given. The fourth member of the group kept track of the commands in order to develop the group's model for what instructions a robot would need to be programmed with to draw any picture.

Four pictures were provided to each group to develop their models and to practice giving commands to their robot. Students were given access to various materials if they wanted to use them including protractors, graph paper, compasses, computers, and rulers. Figure 1 shows the four pictures along with what mathematics I thought students might use in giving directions to draw the pictures including the use of mathematical vocabulary. Students were able to pick which of the four pictures that they would use and were encouraged to try at least two of the pictures.

The data that was collected included audio recordings of each group and students' written work. There were four groups of students. The data was analyzed by writing a narrative of each group's model that was developed (Patton, 2001). Also, the data was coded for what mathematics the students used as they developed their models and in their final models. This was guided by a framework that I developed when I designed the MEA for what mathematics students might use. 


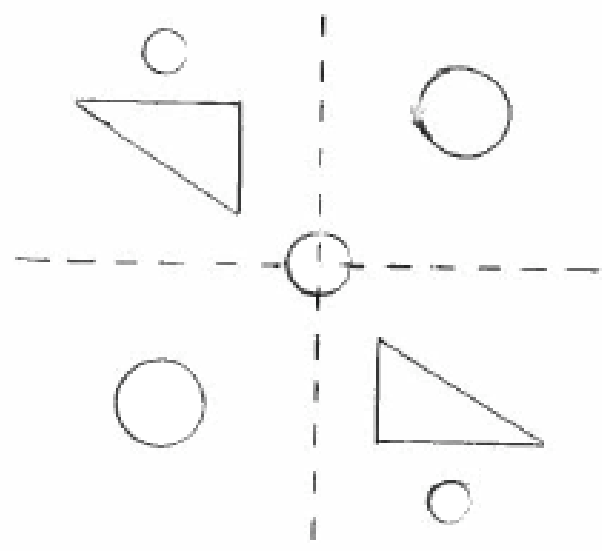

Picture 1: Possible mathematics

-Symmetry

-Shapes including right triangles

-Quadrants

-Coordinate plane

-Congruent

-Rotation

-Reflection

-Compass usage including radius

-Measurement

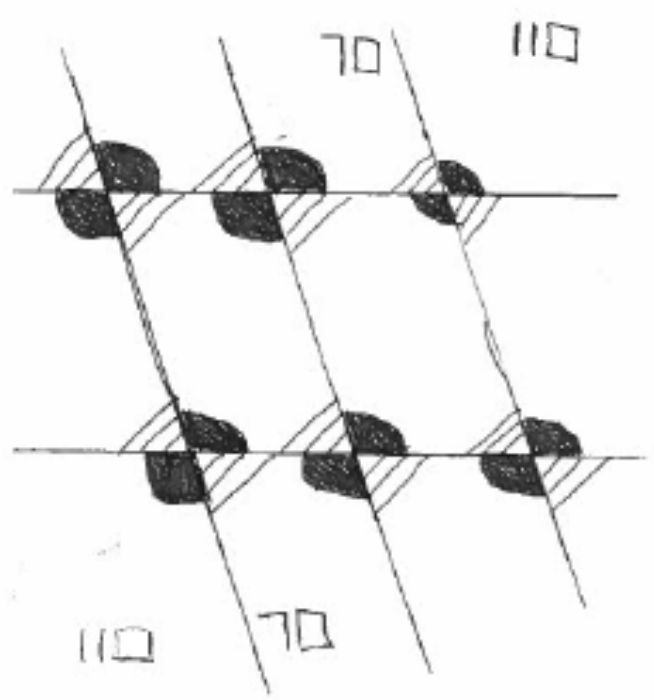

Picture 3: Possible mathematics

-Parallel lines

-Supplementary angles

-Vertical angles

-Measuring and drawing angles with a protractor -Measurement

-Congruent

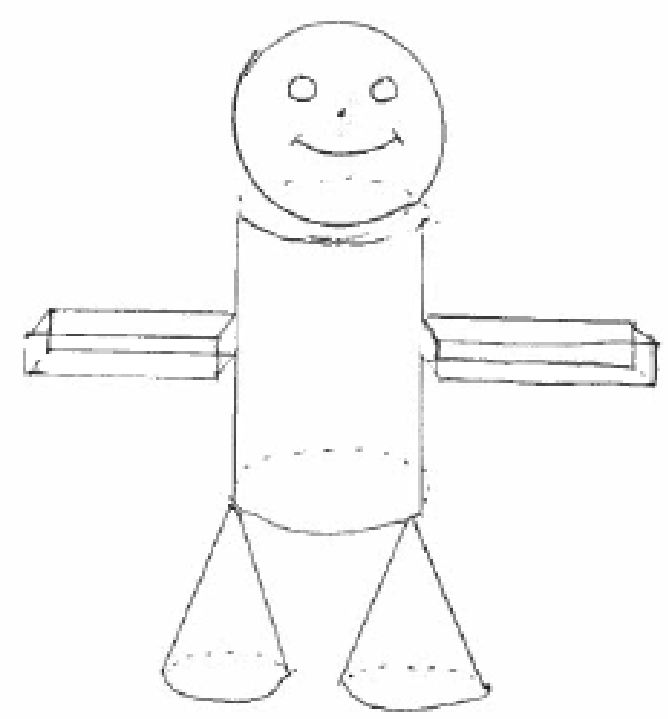

Picture 2: Possible mathematics

-Circle

-Point

-3-dimensional figure

-Right rectangular prism

-Congruent

-Cone

-Cylinder

-Compass usage including radius

-Measurement

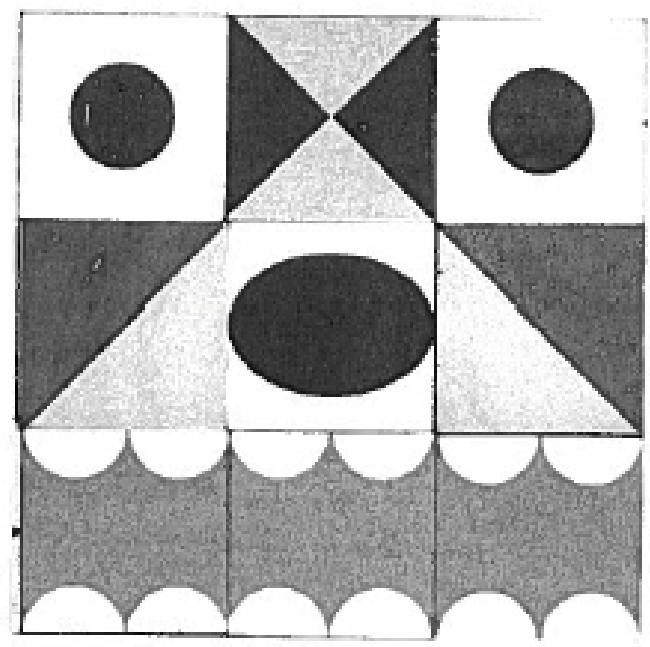

Picture 4: Possible mathematics

-Shapes including right triangles

$-1 / 2$ of a shape

-Measurement

-Symmetry

-Compass usage including radius

-Congruent

Figure 1. Sample pictures along with possible mathematics students could use 


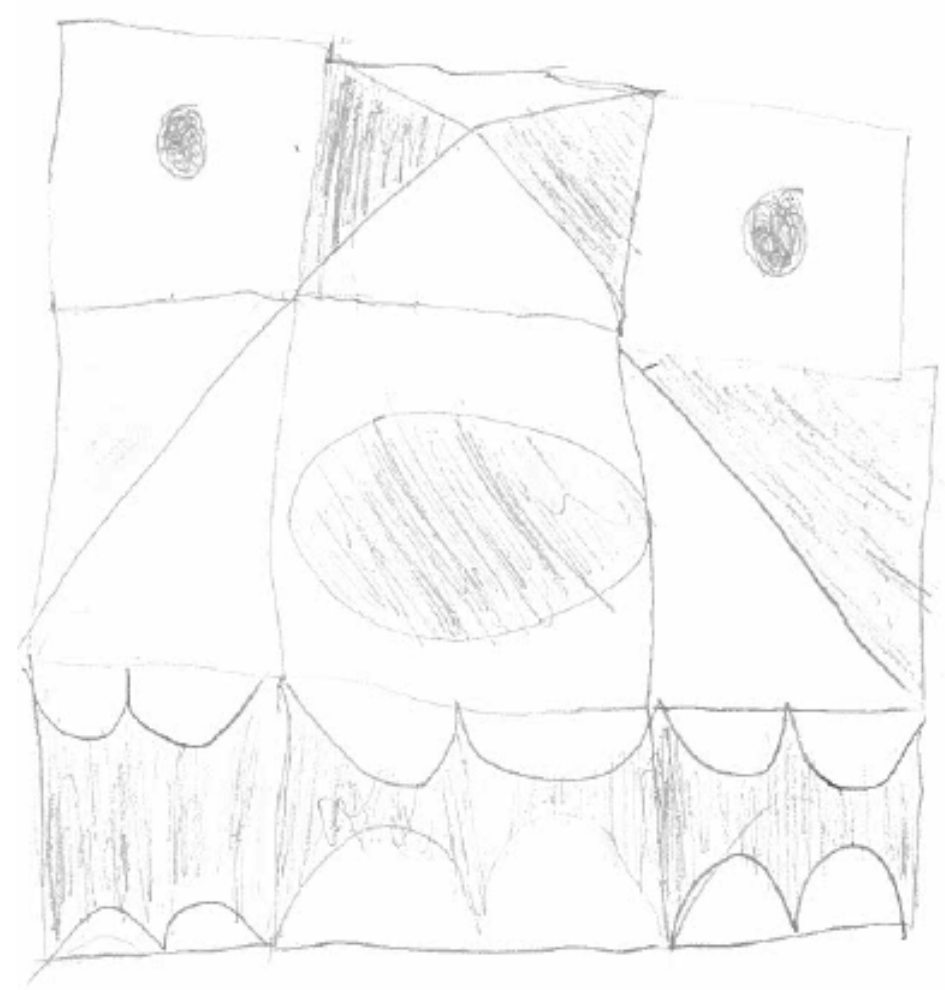

Figure 2. Group 1's created picture

\section{RESULTS}

Each group's development of their ideas will be described along with the mathematics that was used. At the beginning of each group's description I summarize the commands that the recorder for each group wrote down.

\section{Group 1}

Group 1 ended up using directions — up, down, left, right—, a stop command, an erase command, shapes, shading, a loop command, measurement lengths, and a placement command for where the robot was to begin drawing. They were able to have time to just attempt picture 4. Their final product is shown in Figure 2.

They had trouble getting started at first and found giving clear directions was difficult. The student that was the robot several times had to question the direction givers or give them feedback on what they could improve on. For example, "You have to tell me when to stop." "How far up? Which way?" "You have to give me inches. How far right? How far to the left?"

Initially the direction givers had the robot draw shapes that were in the picture, but did not tell the robot how big to make the shapes or what type of triangle to draw. "One inch above the oval make a triangle." Later on, they used general terms such as small, medium, and large for shapes. The direction givers attempted to use measurement lengths as a way to position the objects for the robot, but ended up using lengths only a couple of times. The robot was supposed to just follow the directions given or do nothing if they were not clear. The student that was the robot told the other students what he thought a better way to do this was. "Just tell me to draw a line and then tell me when to stop." The direction givers switched to this method and also ended up pointing on the paper where the robot was to start drawing. They used directions and a stop command for the robot to draw. "Go down. Stop. Go to the left and stop." Even with this method, the direction givers found they needed to have the robot erase several times because they did not say stop soon enough or the directions for what to do were not clear. One example were the directions, "Draw a line from this corner to this corner." The robot drew past where the line was intended.

This group also used a shade command for where the robot was to shade as well as shapes including semicircles for the bottom row of the picture. After getting the robot to draw the bottom left square of the picture, they then told the robot to repeat the same method for the bottom middle and bottom right square, similar to a loop or repeat command for a code sequence. While not using the terminology congruent, the students also told the robot to draw the same triangle to finish the part of the picture in the top row, middle square. 


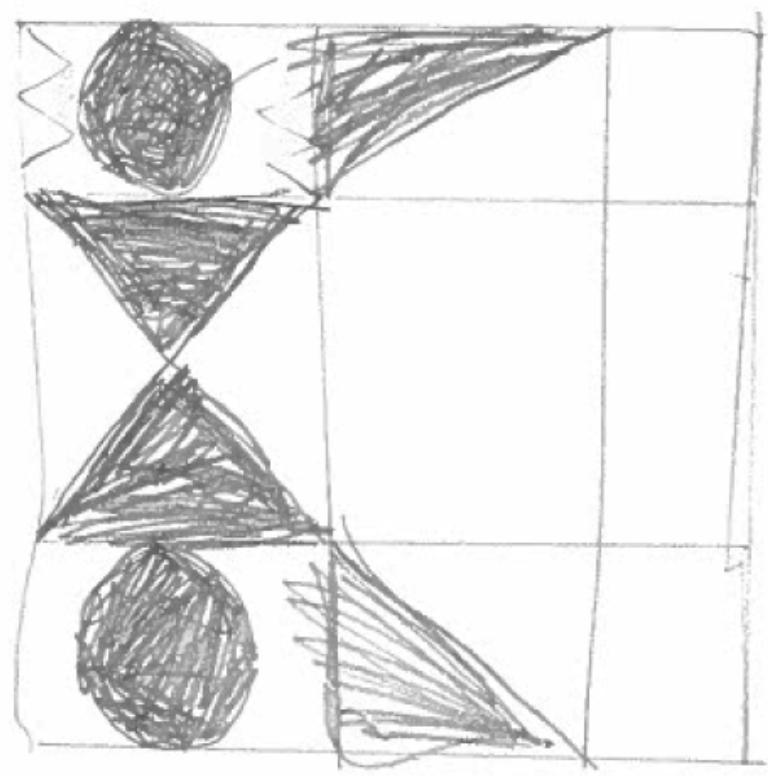

Figure 3. Group 2's created picture

\section{Group 2}

Group two used the following methods to tell their robot how to draw: measurement lengths, shapes, shading, a repeat command, and an erase command. They made use of multiple vocabulary terms including $\mathrm{x}$-axis, $\mathrm{y}$-axis, radius, origin, congruent, and diagonal. They used quadrants as well but did not use the term quadrant. For example, quadrant 2 on the coordinate plane was described as the negative, positive coordinate.

They selected picture 1 and also did the same picture as group 1, but used a different orientation for this picture. One of the group members took their robot's version of picture 1 with them so this picture cannot be shown but picture 2 is shown in Figure 3. They did not have time to finish the full picture.

Group 2 also had trouble with giving clear directions at first, but like group 1 found a method that worked. For picture 1 the direction givers had the robot draw an $\mathrm{x}$-axis and a y-axis to begin. Next one of the direction givers said, "draw a circle in the middle." The recorder commented "If just asked to draw a circle, a robot would not know where to draw or how big. Robots can't assume." The direction givers tried to be more precise after this, but also kept in mind that the picture did not have to look exactly like the original. Because of this, this group also talked about small, medium, and large descriptions for their shapes at first. The direction giver said to make a small circle centered at the origin. For the rest of the circles, this group gave an exact length of the radius for the circles to be drawn. This group was clear on the type of triangles to draw in their picture in that they were right triangles.

For picture 4, the group started by getting nine squares drawn to set up the picture. They started with one square, giving the side lengths as 3 inches. They then told the robot to "draw lines going down in the square an inch from each other. You will have three rectangles then in the square." Similar to group 1 they also used a repeat command to fill in part of the picture with the top left similar to the bottom left.

One of the direction givers initially told the robot to make congruent triangles but changed his mind to a different method. He instead decided to use two diagonals. "On the left middle square make a diagonal line just on the inside from the bottom left to the top right. Repeat the diagonal now on the bottom right to the top left." This group also used a shade command. After hearing group 1's ideas they also stated they would use directions -left, right, up, and down.

\section{Group 3}

Group 3 used the following ideas in programming their robot: graph paper with numbering the lines, an erase command, and directions-left, right, up, and down. They also used the following vocabulary: square, circle, radius, diameter, cylinder, cone, diagonal, and triangle. This group had a difficult time in giving directions and communicating in general as a group. They also switched who was the robot so three of the group members were the robot for certain times. After starting with picture 4, the group quickly switched robots and then tried picture 2. They came back to picture 4 later with a new robot. Their final pictures are shown in Figure 4. It should be noted that since they switched who was the robot, the $2^{\text {nd }}$ and $3^{\text {rd }}$ robot was able to see the pictures ahead of time. 

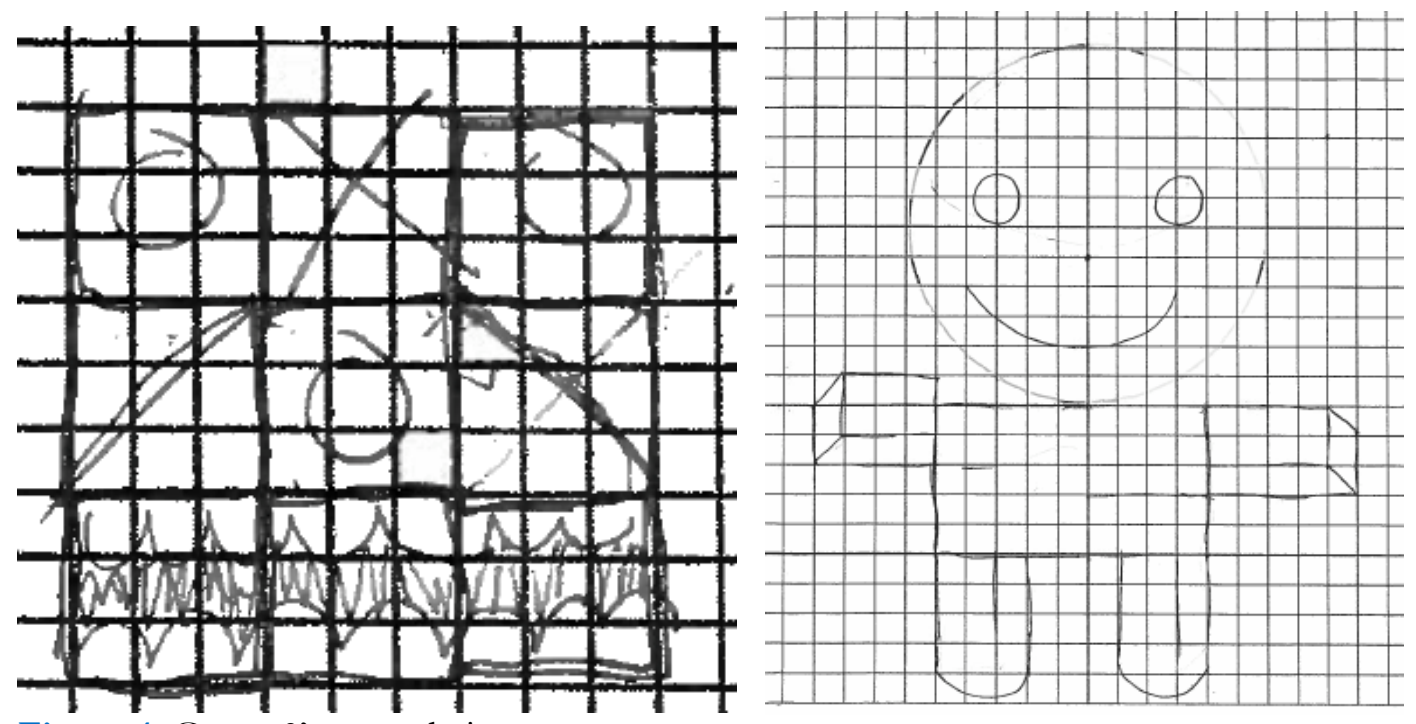

Figure 4. Group 3's created pictures

For picture 4, this group attempted to set up the picture first using nine, 3 × 3 squares. The direction givers attempted to have the first robot do this, but the robot did not know what to do. A direction giver stated, "Draw a $3 \times 3$ square that is 9 units big." The robot questioned the directions given: "Be more descriptive. I don't know what a 9 unit square is...Yeah, but where should I put it?" After this the group switched to picture 2.

The first robot then gave the directions, which started, "Draw a circle." The new robot then had several questions based on this: "Where? How big? What's the radius? What's the diameter? What's the circumference?" The direction givers then decided to number the lines on the graph paper so that they could count how far to the right and how far down to make the objects. For example, "Go back to the $16^{\text {th }}$ line and draw a line horizontal, then 2 units down and 4 units backwards." They also at times told the robot to start and stop drawing once they got to the right starting position. They had some difficulties in getting the arms drawn on picture 2. One direction giver stated, "Make the arms 4 units wide, next to the cylinder." The other direction giver quickly noted, "She cannot see the picture." Another direction for this was to make the rectangle 3-dimensional, which the robot was able to know how to do.

When the group switched back to picture 4 , they were able to set up their picture with nine $3 \times 3$ squares with the new robot understanding the directions to draw $3 \times 3$ squares. At one point one of the direction givers got frustrated when the robot was not drawing what she intended. The direction giver ended up taking the pencil and just drawing what she wanted. Group 3 was able to come up with a method that worked though, but struggled with giving clear communication. The group learned the importance of proper vocabulary and what is clear to oneself is not always clear to another person when communicating.

\section{Group 4}

Group 4 used the following ideas in drawing their picture: measurement, circles, right triangles, radius, quadrants, shade command, erase command, repeat command, and lines. Of all of the four groups they had the easiest time communicating and coming up with an efficient and clear method. This group started with picture 1 and ended up with a picture that looked almost exactly like that of picture 1. The direction givers had the robot make a dotted line down the center of the paper and then a dotted line through the center horizontally. After this the recorder mentioned that they could have just told the robot to make an $\mathrm{x}$ and $\mathrm{y}$ axis. This group used exact measurements for their circles in picture 1. For example, telling the robot to "make a circle with a 1 inch radius in the center."

They decided to label each of the four parts of picture 1 as quadrants. They did not use the conventional system for this but started in the top left as quadrant 1 , then the top right as quadrant 2 , then the bottom left as quadrant 3 , and the bottom right as quadrant 4 . They had a little trouble with drawing the right triangles when they used the direction, "Now in quadrant 1 put an upside down right triangle." The robot drew the right triangle in the wrong orientation so the direction givers had to ask the robot to erase. The direction of "with a line on the right" was good enough to have the correct orientation. The rest of the shapes were able to placed in the picture without any erasing.

The group then proceeded to do picture 4 without any erasing and with the robot only asking one clarifying question. For this picture one of the direction givers switched to being the robot because it seemed fun. The directions to the robot started with drawing a tic-tac-toe board. Then the group had the robot draw $1 / 2$ circles and repeat this to fill in the bottom row of the picture. After this the group decided to label each of the squares as quadrants starting in the top left as quadrant 1 , the top middle as quadrant 2 , the top right as quadrant 3 , the middle 


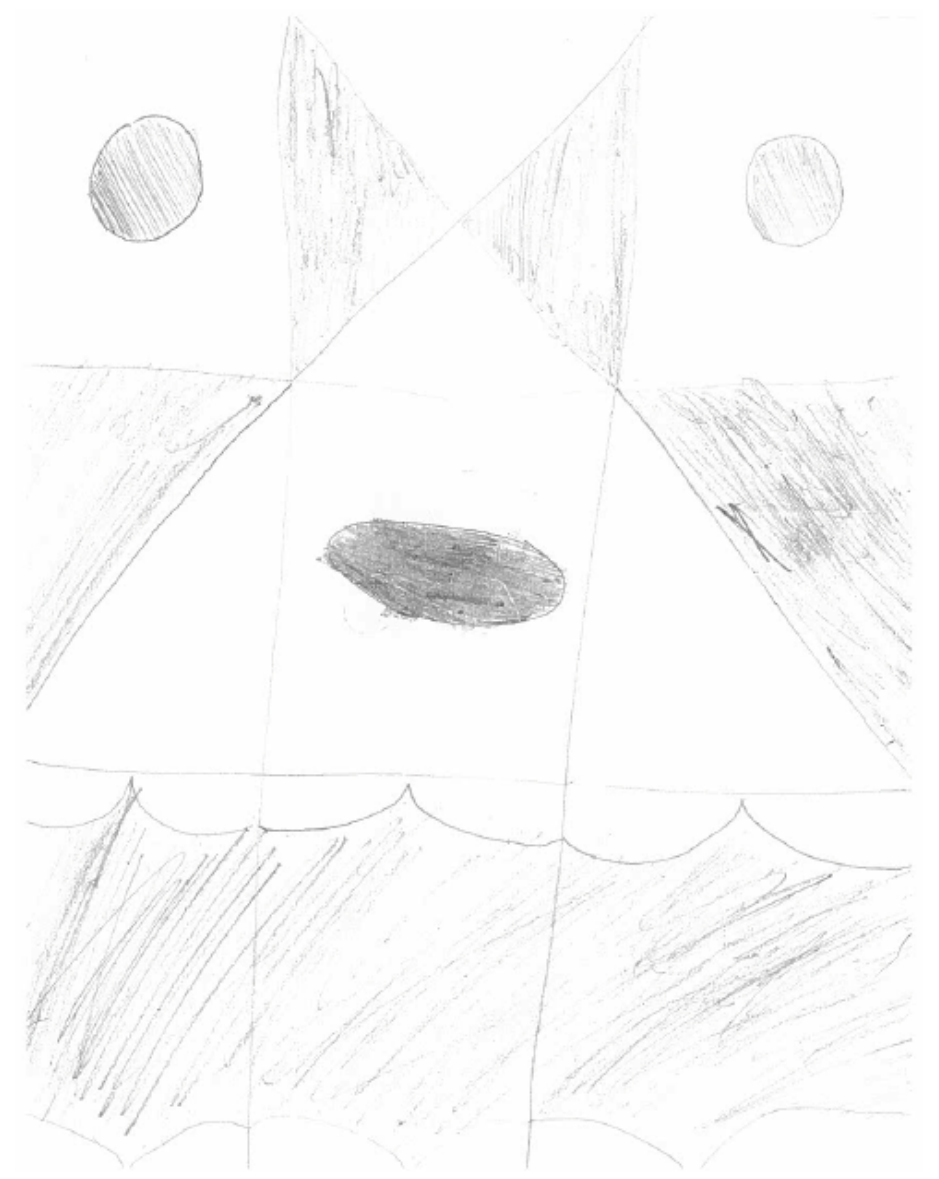

Figure 5. Group 4's created picture

left as quadrant 4 and continuing in this manner. One of the direction givers stated, "In quadrant 1 make a circle." The robot questioned, "What is the radius?" and was told 1-inch. One of the other methods this group used was to draw in line segments. For example, "Make a line from the bottom right corner of quadrant 6 to the top left corner of quadrant 6." They also had a shade command. For quadrant 2, to let the robot know which of the parts to shade, the direction givers divided up quadrant 2 into 4 quadrants to tell which of the two triangles out of the four that had been created to shade. Figure 5 shows group 4's final picture.

\section{DISCUSSION}

This study was conducted to determine the mathematics that middle school students would use on the Robot Art Model-Eliciting Activity (MEA). The Robot Art MEA focused on the content of geometry and measurement and the students used measurement, various vocabulary, and commands connected to programming. Four groups of diverse urban middle school students were able to understand the difficulties on how to program a robot to recreate a picture.

When faced with difficulties, students were able to use routine metacognitive strategies (Stillman, 2011) to develop a method that would work. At times students had difficulties in communicating clearly but based on the structure of the activity students were able to self-assess the quality of their communication and work towards improvement. One of the benefits of mathematical modeling is that students can develop valuable $21^{\text {st }}$ century competencies including communication and teamwork skills, that will help them in life and in any career.

This study shows that mathematical modeling can help to meet the aims and process standards that standards documents detail. One of the aims of the Australian Curriculum is "to ensure that students are confident, creative users and communicators of mathematics, able to investigate, represent and interpret situations in their personal and work lives and as active citizens" (Australian Curriculum, Assessment and Reporting Authority, 2017). This is echoed in the U.S. Common Core State Standards for Mathematics with the Standard for Mathematical Practice 6: Attend to precision. "Mathematically proficient students try to communicate precisely to others. They try to use clear definitions in discussion with others and in their own reasoning" (Common Core State Standards Initiative, 2010, p.7). In order for this to occur students need to have experiences in which they work in groups on realistic and engaging tasks that let students see how their mathematical knowledge can be applied. 
While students were able to develop methods to recreate pictures, there are modifications that could be made to this activity. No group selected picture three which would require students to use more mathematics in their directions. The other pictures could be replaced with pictures that have been created using mathematics. Ebert (2014) writes about a graphing project where students used Desmos, an online graphing utility, to create an artistic design that uses parts of a number of different graphs. Using Desmos, students can make an artistic design employing points, lines, parabolas, hyperbolas, square root functions, circles, exponential functions, logarithmic functions, sine curves, and tangent curves. In Desmos, it is easy to restrict the domain and range of functions to help create part of a picture by using curly brackets (e.g. $y=4 x+2\{-4<x<-2\}$ ). High school students were able to create cartoon characters and names among other things. The context of the Robot Art MEA could be changed to have the middle school students use Desmos to try to recreate pictures that high school students had created. While middle school students would not have knowledge of all the functions, pictures could be selected that would allow the middle school students to make use of lines, points, circles, and parabolas. Another option would be to have students use Geogebra.

The Robot Art MEA could be used as a possible lead in to work with actual robotics programming. Yuen et al. (2014) in working with elementary and middle school students in a summer robotics camp found that the students were engaged mostly in observing, discussing, and building over programming and planning. The Robot Art MEA can lead students to see the importance of holistic planning and well-chosen commands to lead to the desired results. Robotics has many possible benefits as students' interest in robotics continues to grow and can be used to teach science (Robinson, 2005), engineering (Barak \& Zadok, 2007), and mathematics (Silk, Higashi, Shoop, \& Schunn, 2010). Students' experiences with robotics can also increase their interest in STEM subjects (Grimes, 2012; Kim, Oh, Choi, \& Tsourdos, 2014).

While students did not use all of the possible mathematics designed into the activity, teachers can use MEAs and mathematical modeling as formative assessment to build on students' understandings and further develop ideas that the teacher has in mind to pursue. Students as well learn from each other and assess each other's ideas during group work time and the groups' whole class presentation time. Such assessment provides a rich basis for identifying evolving mathematical understandings that can be further developed.

\section{REFERENCES}

Aliprantis, C. and Carmona, G. (2003). Introduction to an economic problem: A models and modeling perspective. In R. Lesh and H. Doerr, (Eds.) Beyond Constructivism: Models and Modeling Perspectives on Mathematics Problem Solving, Teaching, and Learning (pp. 255-264). New York: Routledge.

Australian Curriculum, Assessment and Reporting Authority (2015). [online] Available at: http:/ /www.australiancurriculum.edu.au/mathematics / curriculum/f-10?layout=1

Australian Curriculum, Assessment and Reporting Authority (2017). Aims. [online] Available at: http:/ /www.australiancurriculum.edu.au/mathematics/aims

Barak, M. and Zadok, Y. (2007). Robotics projects and learning concepts in science, technology and problem solving. International Journal of Technology and Design Education, 19(3), pp. 289-307. https://doi.org/10.1007/s10798-007-9043-3

Blum, W. and Borromeo Ferri, R. (2009). Mathematical modelling: Can it be taught and learnt? Journal of Mathematical Modelling and Application, 1(1), pp. 45-58.

Common Core State Standards Initiative (2010). Common Core Standards for Mathematics. [online] Available at: http://www.corestandards.org/assets/CCSI_Math\%20Standards.pdf

Doerr, H. and English, L.D. (2003). A modeling perspective on students' mathematical reasoning about data. Journal for Research in Mathematics Education, 34(2), pp. 110-136. https:// doi.org/10.2307/30034902

Ebert, D. (2014). Graphing projects with desmos. Mathematics Teacher, 108(5), pp. 1-5.

English, L. and Watters, J. (2005). Mathematical modelling in the early years. Mathematics Education Research Journal, 16(2), pp. 58-79. https://doi.org/10.1007/BF03217401

English, L.D. (2010). Young children's early modelling with data. Mathematics Education Research Journal, 22(2), pp. 24-47. https://doi.org/10.1007/BF03217564

Galbraith, P. and Stillman, G. (2006). A framework for identifying student blockages during transitions in the modelling process. ZDM, 38, pp. 143-162. https://doi.org/10.1007/BF02655886

Gould, H. and Wasserman, N.H. (2014). Striking a balance: students' tendencies to oversimplify or overcomplicate in mathematical modeling. Journal of Mathematics Education at Teachers College, 5(1), pp. 27-34.

Grimes, M. (2012). Transformative multicultural science curriculum: A case study of middle school robotics. Unpublished dissertation. University of Nevada, Las Vegas. 
Harel, G. and Lesh, R. (2003). Local conceptual development of proof schemes in a cooperative learning setting. In R. Lesh and H. Doerr, eds. Beyond Constructivism: A Models and Modelling Perspective on Mathematics Problem Solving, Learning and Teaching. New York: Routledge, pp. 359-382.

Kaiser, G. and Sriraman, B. (2006). A global survey of international perspectives on modelling in mathematics education. ZDM, 38(3), pp. 302-310. https://doi.org/10.1007/BF02652813

Kim, S., Oh, H., Choi, J. and Tsourdos, A. (2014). Using hands-on project with lego mindstorms in a graduate course. International Journal of Engineering Education, 30(2), pp. 458-470.

Lesh, R. and Carmona, G. (2003). Piagetian conceptual systems and models for mathematizing everyday experiences. In R. Lesh and H. Doerr, eds. Beyond Constructivism: A Models and Modelling Perspective on Mathematics Problem Solving, Learning and Teaching. New York: Routledge, pp. 71-96.

Lesh, R. and Doerr. (2003). Foundations of models and modelling perspective on mathematics teaching, learning and problems solving. In R. Lesh and H. Doerr, eds. Beyond Constructivism: A Models and Modelling Perspective on Mathematics Problem Solving, Learning and Teaching. New York: Routledge, pp. 3-34.

Lesh, R. and Zawojewski, J. (2007). Problem solving and modelling. In F. K. Lester, Jr., eds. Second handbook of research on mathematics teaching and learning. Reston, VA: National Council of Teachers of Mathematics, pp. 763804.

Lesh, R., Carmona, G. and Moore, T. (2009). Six sigma learning gains and long term retention of understandings and attitudes related to models \& modelling. Mediterranean Journal for Research in Mathematics education, 9(1), pp. 19-54.

Lesh, R., Hoover, M., Hole, B., Kelly, A. and Post, T. (2000). Principles for developing thought-revealing activities for students and teachers. In A. Kelly and R. Lesh, eds. Research Design in Mathematics and Science Education. Mahwah, NJ: Lawrence Erlbaum and Associates, pp. 591-646.

Maiorca, C. and Stohlmann, M. (2016). Inspiring students in integrated STEM education through modeling activities. In C. Hirsch and A.R. McDuffie, eds. Annual Perspectives in Mathematics Education 2016: Mathematical Modeling and Modeling Mathematics. Reston, VA: NCTM, pp.153-161.

McClain, K. (2003). Task-analysis cycles as tools for supporting students' mathematical development. In R. Lesh and H. Doerr, eds. Beyond Constructivism: A Models and Modelling Perspective on Mathematics Problem Solving, Learning and Teaching. New York: Routledge, pp. 175-190.

Mousoulides, N. and English, L.D. (2011). Engineering model eliciting activities for elementary school students. In G. Kaiser, W. Blum, R. Borromeo Ferri and G. Stillman, eds. Trends in Teaching and Learning of Mathematical Modelling. New York: Springer, pp. 221-230. https://doi.org/10.1007/978-94-007-0910-2_23

Mousoulides, N., Christou, C. and Sriraman, B. (2008). A modeling perspective on the teaching and learning of mathematical problem solving. Mathematical Thinking and Learning, 10, pp. 293-304. https://doi.org/10.1080/10986060802218132

Mousoulides, N., Pittalis, M., Christou, C. and Sriraman, B. (2010). Tracing students' modeling processes in school. In R. Lesh, P. Galbraith, C. Haines and A. Hurford, eds. Modeling Students' Mathematical Modeling Competencies. New York: Springer, pp. 119-129. https://doi.org/10.1007/978-1-4419-0561-1_10

Mousoulides, N., Sriraman, B., Pittalis, M. and Christou, C. (2007). Tracing students' modelling processes in elementary and secondary school. In D. Pitta and G. Philippou, eds. Proceedings of the fifth Congress of the European Society for Research in Mathematics Education. Larnaca, Cyprus: European Society for Research in Mathematics Education, pp. 2130-2139.

Ng, K.E.D. (2011). Mathematical knowledge and application and student difficulties in a design-based interdisciplinary project. In G. Kaiser, W. Blum, R. Borromeo Ferri and G. Stillman, eds. Trends in teaching and learning of mathematical modelling. New York: Springer, pp. 107-116. https://doi.org/10.1007/978-94-007-09102_12

OECD (2013). Mathematics Framework. In PIS A 2012 Assessment and analytical framework: mathematics, reading, science, problem solving and financial literacy, OECD Publishing.

Patton, M. (2001). Qualitative research and evaluation methods. Thousand Oaks, CA: Sage Publications.

Robinson, M. (2005). Robotics-driven activities: Can they improve middle school science learning? Bulletin of Science, Technology and Society, 25(1), pp. 73-84. https://doi.org/10.1177/0270467604271244

Silk, E., Higashi, R., Shoop, R. and Schunn, C. (2010). Designing technology activities that teach mathematics. The Technology Teacher, 69(4), pp. 21-27.

Stillman, G. (2011). Applying metacognitive knowledge and strategies in applications and modelling tasks at secondary school. In G. Kaiser, W. Blum, R. Borromeo Ferri and G. Stillman, eds. Trends in teaching and learning of mathematical modelling. New York: Springer, pp. 165-180. https://doi.org/10.1007/978-94-007-0910-2_18

Stillman, G., Brown, J. and Galbraith, P. (2010). Identifying challenges within transition phases of mathematical modeling activities at year 9. In R. Lesh, P. Galbraith, C. Haines and A. Hurford, eds. Modeling students' 
mathematical modeling competencies. New York: Springer, pp. 385-398. https://doi.org/10.1007/978-1-4419-0561$1 \_33$

Stohlmann, M. (2017). Elementary mathematical modeling: Get in the GAIMME. Banneker Banner Journal, 30(2), pp. 4-11.

Stohlmann, M. and Albarracin, L. (2016). What is known about elementary grades mathematical modelling. Education Research International, 2016, pp. 1-9. https://doi.org/10.1155/2016/5240683

Stohlmann, M., Maiorca, C. and Olson, T. (2015). Preservice secondary teachers' conceptions from a mathematical modeling activity and connections to the Common Core State Standards. The Mathematics Educator Journal, 24(1), pp. 21-43.

Yuen, T., Boecking, M., Tiger, E., Gomez, A., Guillen, A., Arrequin, A. and Stone, J. (2014). Group tasks, activities, dynamics, and interactions in collaborative robotics projects with elementary and middle school children. Journal of STEM Education, 15(1), pp. 39-45.

\section{APPENDIX}

\section{Robot Art MEA}

Max Chandler says that working with robots is the only way he can create the pictures he wants. Built from Lego bricks and aluminum, the robots look like miniature trucks and cranes. Some propel themselves on wheels, while others shuffle about on legs. Chandler's intention has always been to infuse his art with mathematics. An avid painter since childhood, he has loved math for almost as long: at nine, he was already writing computer programs. He went on to study math at MIT and has paid the bills working as a programmer. "I have always had this dual nature of being tied up in science and in art," he says. Simply rendering mathematical patterns on a computer and printing them out created boring and repetitive pictures. To get the shapes he wanted, he could program small robots to drag a paint brush or pen as they moved.

You might wonder if Chandler feels the end result is worth all the effort. His answer is a resounding yes. "It wouldn't be the same if it was just the robot or just me," he says. "Even if a viewer doesn't know why it is, the picture will look different." Whether the robots create something better than a human could is subjective, of course, but the pictures are unique. People say, "Wow, those lines are special -- how did you do that?"
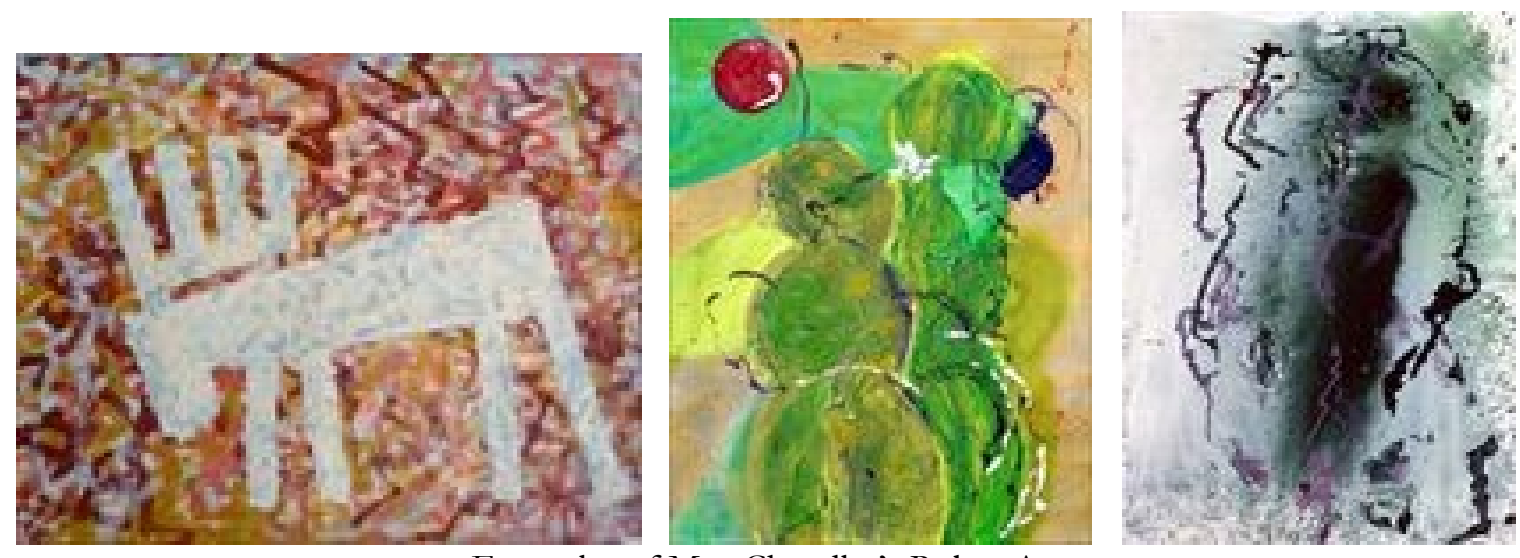

Examples of Max Chandler's Robot Art

\section{"Robot Art" Questions}

1) How is Max Chandler's art different from a lot of other art?

2) Why does he use robots instead of a computer and printer?

3) What did Max Chandler study at college at MIT? How does he use this knowledge as an artist?

4) How can robots help to improve our lives?

\section{Telling a Robot Artist How to Draw}

For the National Robotics Challenge, there is a special competition to design and build an Art Robot. A team from the local high school has built a robot that can draw dots, lines, and common shapes like circles, arches, squares, triangles, ovals, trapezoids, and rectangles. The robot works great, but the team is having problems getting the robot to make "art" rather than just draw dots, lines, and shapes. 
They think it would be cool to have the robot recreate a picture like those below by following spoken directions from someone. They plan to ask one of the judges to draw a picture and then one of the high school team members will tell the robot how to draw its own version of that picture.

The high school team is working hard on reprogramming the robot to accept spoken directions, but they need your help to know what directions they should say to the robot to make pictures like these. They have asked your team for help finding out how to tell a robot to draw its own version of a picture like the one below.

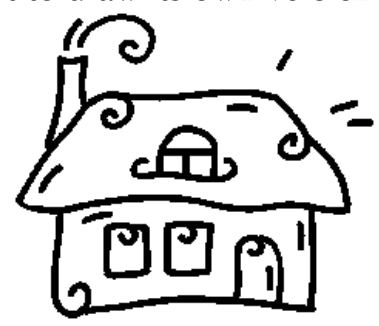

Your team has agreed to help the high school robotics team. Your team will make a set of instructions explaining how to tell a robot to draw a picture. The high school robotics team has given your team the following information to help you understand how a robot "thinks" and what they need from you:

1) One person on your team should be able to look at a picture and tell another person on your team how to draw a picture even though the person drawing has never seen the picture. There are sample pictures in the envelope provided so you can try this out in your group.

2) The person drawing the picture is pretending to be the robot; so, they have to follow directions exactly as they are given. If just asked to draw a circle, a robot would not know where to draw the circle or how big to make it. All instructions need to be very specific.

3) We want the robot to truly be an "artist" able to draw anything (like a picture made by a judge); so, we need instructions for how to tell the person drawing or robot about any picture not just one particular picture.

4) The new pictures need to look like the original picture but do not have to be exactly the same. Our robot is an artist with its own style.

Your team needs to make instructions describing what a robot should be told so that it draws a picture. Your team will present these instructions to the high school robotics team to help them understand what to do at their competition. 